\title{
Atrial Myocardial Deformation Changes in Patients with Non-Valvular Atrial Fibrillation
}

\author{
Mohamed Elnoamany¹, Naglaa Fahim1, Mohsen Abdelfattah ${ }^{2}$ \\ ${ }^{1}$ Cardiology Department, Faculty of Medicine, Menoufia University, Menoufia, Egypt \\ ${ }^{2}$ Cardiology Department, Sadat City General Hospital, Menoufia, Egypt \\ Email: mnoamany@hotmail.com,dr.mohsen.allaam@gmail.com
}

How to cite this paper: Elnoamany, M., Fahim, N. and Abdelfattah, M. (2021) Atrial Myocardial Deformation Changes in Patients with Non-Valvular Atrial Fibrillation. World Journal of Cardiovascular Diseases, $11,357-371$.

https://doi.org/10.4236/wjcd.2021.118035

Received: July 22, 2021

Accepted: August 23, 2021

Published: August 26, 2021

Copyright $\odot 2021$ by author(s) and Scientific Research Publishing Inc. This work is licensed under the Creative Commons Attribution International License (CC BY 4.0).

http://creativecommons.org/licenses/by/4.0/

\begin{abstract}
Background: Atrial fibrillation (AF) is the most common cardiac arrhythmia. It increases cardiovascular morbidity, especially embolic stroke and mortality. Two-dimensional speckle tracking echocardiography (2D STE) is a useful method that has been used to detect changes in atrial myocardial deformation in AF patients. Objectives: To study atrial myocardial deformation changes in patient with non-valvular AF using 2D STE. Patients and Methods: This study included 25 patients with non-valvular AF and 25 normal healthy controls. 2D STE was used for assessment of strain and strain rate of septal and free walls of both right atrium (RA) and LA and left ventricle (LV). Results: Mean LA septal and lateral strain and strain rate were significantly reduced in the AF group compared to the control group $(-7.2 \% \pm 5.2 \%$ vs. $-20.4 \% \pm$ $3.9 \%,-8.7 \% \pm 8.8 \%$ vs. $-21.7 \% \pm 3.4 \%)$ and $\left(-0.9 \pm 0.5 \mathrm{~S}^{-1}\right.$ vs. $-1.9 \pm 0.4 \mathrm{~S}^{-1}$, $-1.1 \pm 0.6 \mathrm{~S}^{-1}$ vs. $-2.04 \pm 0.3 \mathrm{~S}^{-1}$ ) respectively. Mean RA septal and lateral strain and strain rate were significantly reduced in the AF group compared to the control group $(-5.9 \% \pm 6.1 \%$ vs. $-23.4 \% \pm 4.5 \%,-8.9 \% \pm 9.3 \%$ vs. $-21.7 \% \pm 3.4 \%)$ and $\left(-0.98 \pm 0.6 \mathrm{~S}^{-1}\right.$ vs. $-1.9 \pm 0.3 \mathrm{~S}^{-1},-1.3 \pm 0.9 \mathrm{~S}^{-1}$ vs. -2.1 $\pm 0.5 \mathrm{~S}^{-1}$ ) respectively. Mean LV global longitudinal strain (GLS) and strain rate were significantly reduced in the $\mathrm{AF}$ group compared to the control group $(-8.8 \% \pm 4.6 \%$ vs $-19.6 \% \pm 2.4 \%)$ and $\left(-0.8 \pm 0.3 \mathrm{~S}^{-1}\right.$ vs $\left.-1.5 \pm 0.4 \mathrm{~S}^{-1}\right)$ respectively $(\mathrm{P}<0.001$ for all). Conclusion: $\mathrm{AF}$ is a bi-atrial disease, $\mathrm{LA}$ and RA myocardial deformation properties as well as LV GLS and strain rate measured by $2 \mathrm{D}$ STE were significantly impaired in AF patients compared to healthy controls.
\end{abstract}

\section{Keywords}

Myocardial Deformation, Non-Valvular Atrial Fibrillation, Speckle Tracking Echocardiography, Strain, Strain Rate 


\section{Introduction}

Atrial fibrillation (AF) is the most common cardiac arrhythmia. It increases cardiovascular morbidity, especially embolic stroke and mortality [1]. Ischemic stroke (IS) is one of the five leading causes of death worldwide [2] and 20\% $30 \%$ of the incidents are estimated to be caused by atrial fibrillation (AF) [3] AF is actually a bi-atrial disease. As seen in the LA, histological studies of right atrium (RA) myocardium in AF show the same substrate of patchy fibrosis, inflammatory cell infiltrate, necrosis, and vascular degeneration that may contribute in pathogenesis of AF [4]. Tissue Doppler imaging (TDI) and two-dimensional (2D) speckle tracking are two echocardiographic techniques to assess atrial strain. The technique is highly feasible for studying the contractility of myocardial tissue, allowing the quantification of low-velocity, high amplitude, and long-axis intrinsic myocardial velocities in both systole and diastole [5]. Two-dimensional speckle tracking echocardiography (2D STE) is a useful method that has been used to detect changes in atrial myocardial deformation in AF patients [6]. Myocardial strain $(\varepsilon)$ and strain rate (SR) are measures of myocardial performance that have been proven to accurately assess myocardial contractility [7] [8]. During $\mathrm{AF}$, electrical activation pathway is disrupted and atrial mechanical performance becomes abnormal. As a consequence, complete loss of atrial pump function occurs, demonstrated by the absence of one of the two negative strain rate curves during diastole, which is the most characteristic pattern during AF [5]. LA longitudinal strain has been described to be associated with the amount of fibrosis within the LA wall allowing a complex assessment of LA structure and function [9]. RA remodeling has been reported in AF, but few studies have focused upon it as a risk factor for AF recurrence [10].

\section{Patients and Methods}

\subsection{Study Population}

This study had been conducted on 25 patients with documented non-valvular $\mathrm{AF}$, and 25 healthy subjects without cardiovascular disease, hypertension, or diabetes mellitus had been enrolled as controls. We included patient with long standing persistent non-valvular AF and AF duration $>1$ year. We excluded Congenital heart diseases, valvular AF mainly rheumatic heart diseases, patient with cardiogenic shock and needed inotropes or hemodynamic instability and needed DC shock or mechanical ventilation. Each included patient was subjected to full history taking, thorough clinical examination, 12 lead Electrocardiogram.

\subsection{Conventional Echocardiography}

Transthoracic echocardiography was performed on the subjects at rest in the left lateral decubitus position using a Vivid S 6 (GE Vingmed, Horten, Norway) equipped with a harmonic S3 variable frequency (1.7 - $4 \mathrm{MHz})$ Phased-array transducer and conventional parameters measured in apical 4 chambers, apical two camber, apical three chambers and parasternal views: end diastolic dimen- 
sion and volume (LVIDd, and EDV), end systolic dimension and volume (LVIDs and ESV), Fractional shortening (FS), EF, septal and posterior wall thickness (LVSWT and LVPWT), RA and LA diameters.

\subsection{Assessment of LA, RA and LV Strain and Strain Rate}

Offline analysis of raw ultrasound data was performed at Menoufia University-Department of Cardiology using GE Echopac and the following views were taken for analysis; apical 4 chamber view, apical 2 chamber view, and apical long axis view. All analyzed images were recorded with a frame rate of at least $40 \mathrm{fps}$ for reliable analysis by the software. First, LA and RA walls borders were traced manually in apical 4 chamber view just before the QRS complex, at its minimum volume. Definition of RA and LA endocardial border enabled the software to calculate average values of strain and SR for six segments of LA and RA in apical four chamber view as seen in Figure 1, Figure 2. Then the LV end-systolic frame was defined by determining the closure of the aortic valve in the apical long-axis view. Then the LV endocardial border was manually traced at end-systole and the created region of interest was manually adjusted to the thickness of the myocardium. Any segments which subsequently failed to track were automatically discarded by the software for the calculation of global strain. Global longitudinal strain and strain rate for the complete LV segments were provided by the software as seen in Figures 3-5.

\subsection{Statistical Analysis}

Data were collected, tabulated and statistically analyzed using an IBM compatible personal computer with Statistical Package for the Social Sciences (SPSS) version 23 (SPSS Inc. Released 2015. IBM SPSS statistics for windows, version 23.0, Armnok, NY: IBM Corp.).

Two types of statistical analysis were performed:

1) Descriptive statistics e.g. qualitative data were expressed in: Number $(\mathrm{N})$, percentage (\%), while quantitative data were expressed as mean $(\bar{x})$, standard deviation (SD) and range (minimum-maximum).

2) Analytic statistics e.g.

a) Student's t-test is a test of significance used for comparison of quantitative variables between two groups of normally distributed data, while Mann Whitney's test was used for comparison of quantitative variables between two groups of not normally distributed data.

b) Chi-square test $\left(\chi^{2}\right)$ was used to study association between qualitative variables. Whenever any of the expected cells were less than five, Fischer's Exact test was used.

c) Pearson correlation was used to show correlation between two continuous normally distributed variables while Spearman correlation was used for not normally distributed ones.

Significant test results were quoted as two-tailed probabilities. Significance of the obtained results was judged at the $5 \%$ level $(\mathrm{P} \leq 0.05)$. 


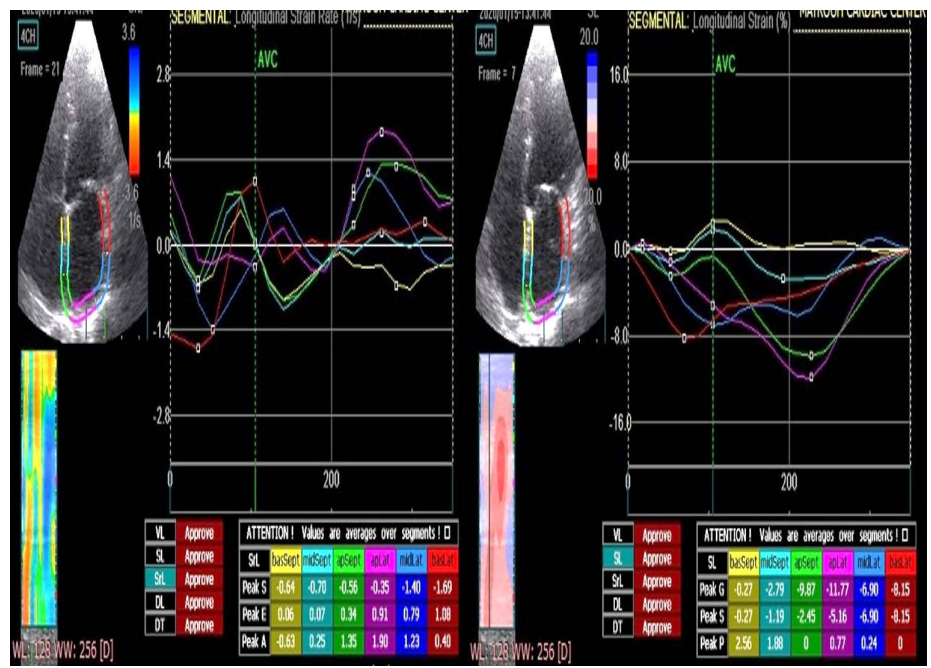

Figure 1. LA strain and strain rate for each wall.



Figure 2. RA strain and strain rate for each wall.

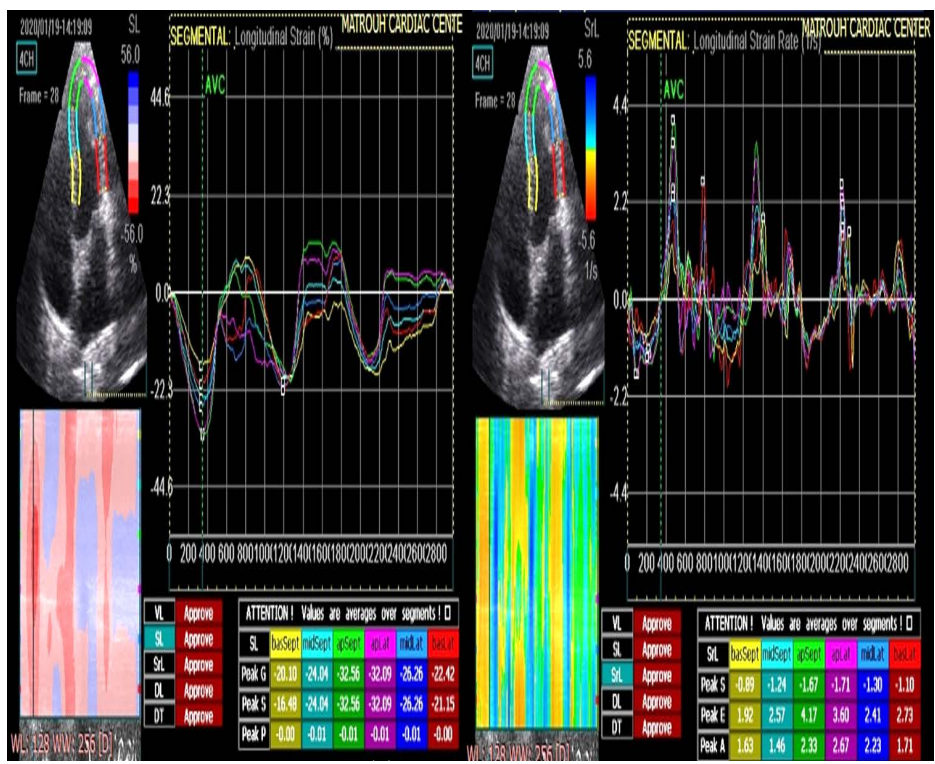

Figure 3. LV A4C srain and strain rate. 




Figure 4. LV A3C strain and strain rate.

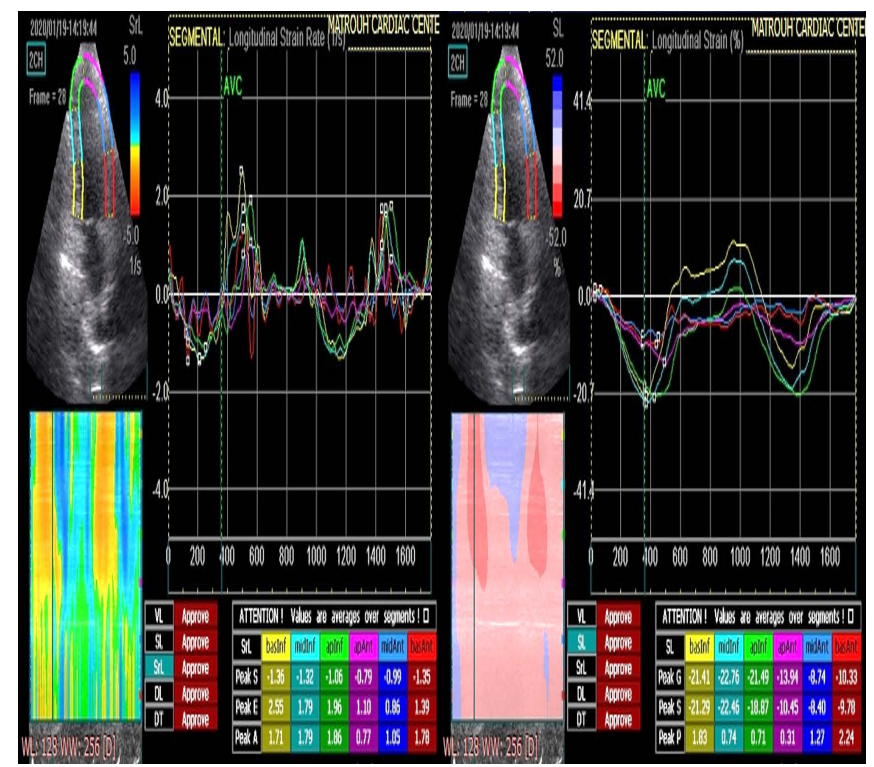

Figure 5. LV A2C strain and strain rate.

\section{Results}

\subsection{Demographic Data}

Regarding the age and sex, as shown in Table 1. This study included AF group mean age was $54.3 \pm 4.9$ years (ranged from 48 - 67 years). Males represented $52 \%$ (13 patients) of the study population while females represented $48 \%$ (12 patients). The control group mean age was $51.9 \pm 6.9$ years (ranged from $39-63$ years). Males represented $68 \%$ (17 men) of the study population and females represented $32 \%$ (8 women). The mean body surface area in AF group and control group was $1.84 \pm 0.14 \mathrm{M} 2$ and $1.82 \pm 0.13 \mathrm{M} 2$ respectively.

\subsection{Assessment of LV, RA and LA Strain}

Table 2 showed that the LV global strain and strain of each wall, the septum, the 
lateral wall, the anterior wall, the inferior wall, the antero-septal wall and the posterior wall were detected to be statistically significantly reduced (P-value < $0.001)$ in the AF group compared to the control group. Also, RA strain $(\varepsilon)$ of each wall the septum and lateral wall were detected to be statistically significantly reduced ( $\mathrm{P}$-value $<0.001$ ) in the AF group compared to the control group, and LA strain $(\varepsilon)$ of each wall the septum and lateral wall were detected to be statistically significantly reduced $(\mathrm{P}$-value $<0.001)$ in the AF group compared to the control group (Figure 6, Figure 8).

Table 1. Demographic data.

\begin{tabular}{ccc}
\hline & $\begin{array}{c}\text { Patients } \\
(\mathrm{AF}=25) \\
\mathrm{N}(\%)\end{array}$ & $\begin{array}{c}\text { Control } \\
(\mathrm{NSR}=25)\end{array}$ \\
Age: & $\mathrm{N}(\%)$ \\
Mean \pm SD & $54.3 \pm 4.9$ & $51.9 \pm 6.9$ \\
Range (Min.-Max.) & $48-67$ & $39-63$ \\
Sex: & $12(48)$ & $8(32)$ \\
Female & $13(52)$ & $17(68)$ \\
Male & $13(52)$ & $0(0)$ \\
DM: & $12(48)$ & $25(100)$ \\
Yes & & $0(0)$ \\
No & $15(60)$ & $25(100)$ \\
HTN: & $10(40)$ & \\
Yes & & $1.82 \pm 0.13$ \\
No & $1.84 \pm 0.14$ & $1.6-2.1$ \\
Body surface area: & $1.6-2.1$ &
\end{tabular}

Table 2. LV, RA and LA strain.

\begin{tabular}{|c|c|c|c|c|}
\hline Wall & Patients $(\mathrm{AF}=25) \%$ & Control $(\mathrm{NSR}=25) \%$ & Test of significance & $\mathrm{P}$-value \\
\hline \multicolumn{5}{|c|}{ LV strain $(\varepsilon)$} \\
\hline $\begin{array}{c}\text { Septal: } \\
\text { Mean } \pm \text { SD } \\
\text { Range }\end{array}$ & $\begin{array}{c}-8.6 \pm 5.1 \\
-0.6:-21.7\end{array}$ & $\begin{array}{c}-20.01 \pm 4.9 \\
-9.3:-26.3\end{array}$ & $\mathrm{t}=8.08$ & $<0.001^{\star *}$ \\
\hline $\begin{array}{c}\text { Lateral: } \\
\text { Mean } \pm \text { SD } \\
\text { Range }\end{array}$ & $\begin{array}{l}-9.8 \pm 7.3 \\
0.1:-29.2\end{array}$ & $\begin{array}{c}-20.2 \pm 4.9 \\
-11.3:-28.8\end{array}$ & $\mathrm{t}=5.93$ & $<0.001^{\star *}$ \\
\hline $\begin{array}{c}\text { Anterior: } \\
\text { Mean } \pm \text { SD } \\
\text { Range }\end{array}$ & $\begin{array}{l}-6.8 \pm 5.6 \\
5.3:-16.9\end{array}$ & $\begin{array}{c}-19.2 \pm 3.2 \\
-13.2:-23.8\end{array}$ & $t=9.73$ & $<0.001^{\star \star}$ \\
\hline $\begin{array}{c}\text { Inferior: } \\
\text { Mean } \pm \text { SD } \\
\text { Range }\end{array}$ & $\begin{array}{l}-10.3 \pm 5.8 \\
-1.8:-27.5\end{array}$ & $\begin{array}{l}-19.8 \pm 2.3 \\
-15.5:-24\end{array}$ & $t=7.61$ & $<0.001^{\star *}$ \\
\hline $\begin{array}{c}\text { Anteroseptal: } \\
\text { Mean } \pm \text { SD } \\
\text { Range }\end{array}$ & $\begin{array}{l}-8.3 \pm 6.5 \\
1.7:-24.3\end{array}$ & $\begin{array}{l}-19.7 \pm 2.7 \\
-15.3:-24.8\end{array}$ & $\mathrm{t}=8.09$ & $<0.001^{\star *}$ \\
\hline $\begin{array}{c}\text { Posterior: } \\
\text { Mean } \pm \text { SD } \\
\text { Range }\end{array}$ & $\begin{array}{l}-9.5 \pm 6.9 \\
9.4:-24.3\end{array}$ & $\begin{array}{c}-19.3 \pm 2.8 \\
-13.3:-24.6\end{array}$ & $\mathrm{t}=6.52$ & $<0.001^{\star *}$ \\
\hline $\begin{array}{l}\text { LV GLS: } \\
\text { Mean } \pm \text { SD } \\
\text { Range }\end{array}$ & $\begin{array}{c}-8.8 \pm 4.6 \\
-3.3:-16.4\end{array}$ & $\begin{array}{c}-19.6 \pm 2.4 \\
-14.8:-21.6\end{array}$ & $\mathrm{t}=8.07$ & $<0.001^{\star *}$ \\
\hline
\end{tabular}




\section{Continued}

\begin{tabular}{|c|c|c|c|c|}
\hline \multicolumn{5}{|c|}{ RA strain $(\varepsilon)$} \\
\hline Septal: & & & \multirow{3}{*}{$\mathrm{t}=11.49$} & \multirow{3}{*}{$<0.001^{\star *}$} \\
\hline Mean \pm SD & $-5.9 \pm 6.1$ & $-23.4 \pm 4.5$ & & \\
\hline Range & 11.8: -17.7 & $-12.7:-33.3$ & & \\
\hline Lateral: & & & \multirow{3}{*}{$t=7.16$} & \multirow{3}{*}{$<0.001^{\star *}$} \\
\hline Mean \pm SD & $-8.9 \pm 9.3$ & $-23.7 \pm 4.5$ & & \\
\hline Range & $16.7:-25.9$ & $-13.1:-32.6$ & & \\
\hline \multicolumn{5}{|c|}{ RA strain $(\varepsilon)$} \\
\hline \multicolumn{5}{|l|}{ Septal: } \\
\hline Mean \pm SD & $-7.2 \pm 5.2$ & $-20.4 \pm 3.9$ & \multirow{2}{*}{$t=10.02$} & \multirow{2}{*}{$<0.001^{\star *}$} \\
\hline Range & 3.6: -17.4 & $-14.2:-29.8$ & & \\
\hline \multicolumn{5}{|l|}{ Lateral: } \\
\hline Mean \pm SD & $-8.7 \pm 8.8$ & $-21.7 \pm 3.4$ & \multirow{2}{*}{$\mathrm{U}=4.96$} & \multirow{2}{*}{$<0.001^{\star *}$} \\
\hline Range & $3.3:-33.4$ & $-15.7:-25.8$ & & \\
\hline
\end{tabular}

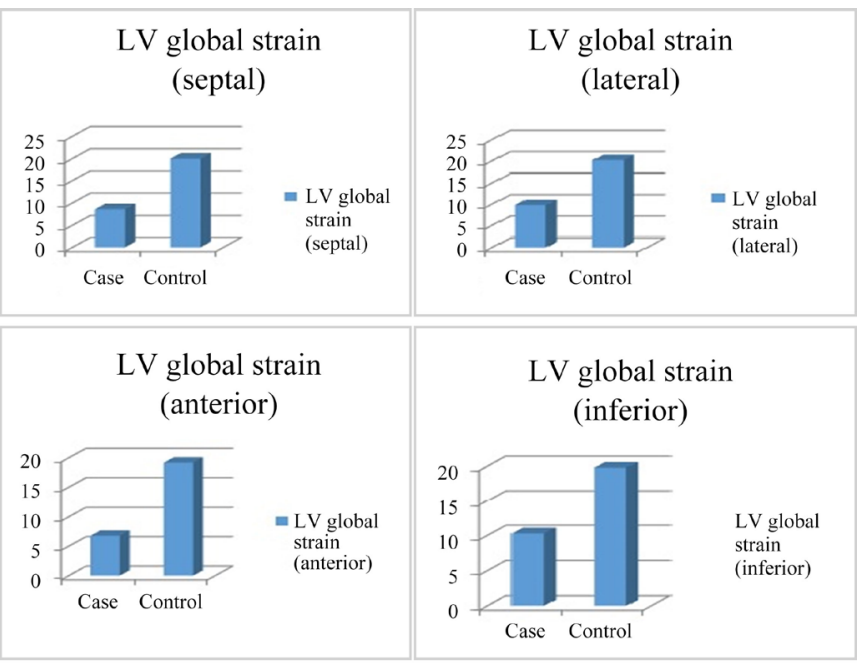

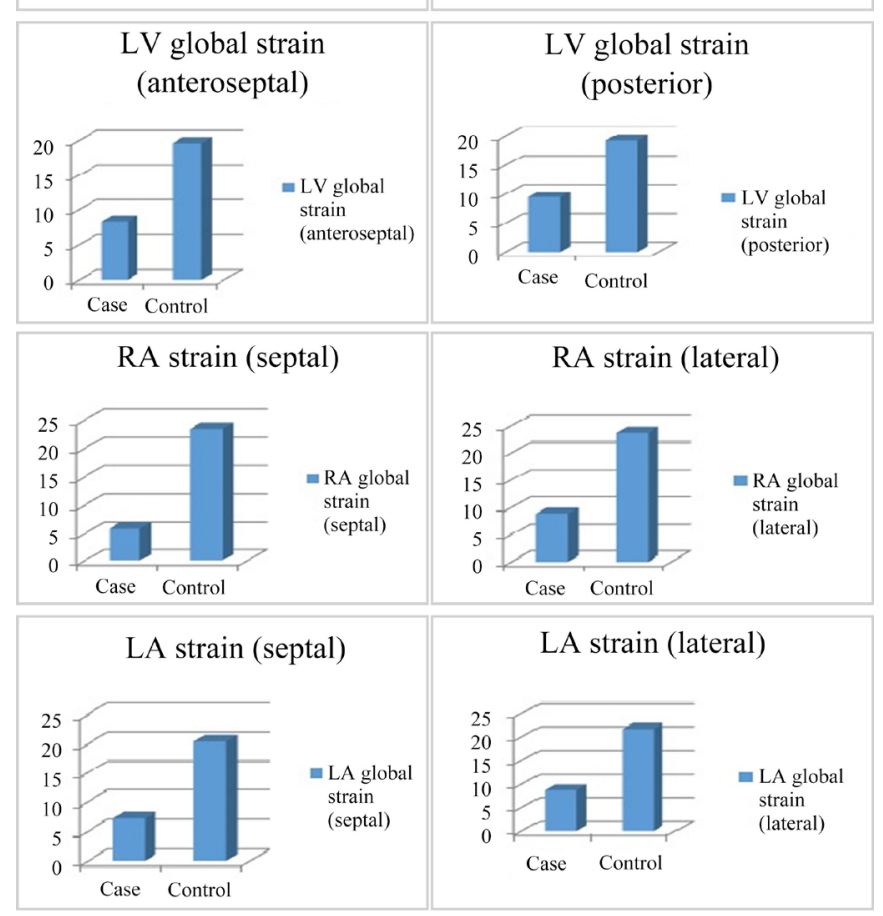

Figure 6. LV, RA and LA strain. 


\subsection{Assessment of LV, RA and LA Strain Rates}

Table 3 showed that LV strain rate (SR) of each wall, the septum, apical, the lateral wall, the anterior wall, the inferior wall, the antero-septal wall and the posterior wall were detected to be statistically significantly reduced (P-value $<0.001$ ) in the AF group compared to the control group. Also, RA strain rate (SR) of each wall the septum and lateral wall were detected to be statistically significantly reduced ( $\mathrm{P}$-value $<0.001$ ) in the AF group compared to the control group. And regarding the lateral wall (basal and mid) were detected to be statistically significantly reduced $(\mathrm{P}$-value $=0.037, \mathrm{P}$-value $=0.001$ respectively) in the $\mathrm{AF}$ group compared to the control group), and LA strain rate $(\varepsilon)$ of each wall the septum and the lateral wall were significantly reduced $(\mathrm{P}$-value $<0.001$ ) in the AF group compared to the control group (Figure 7).

Table 3. LV, LA and RA SR.

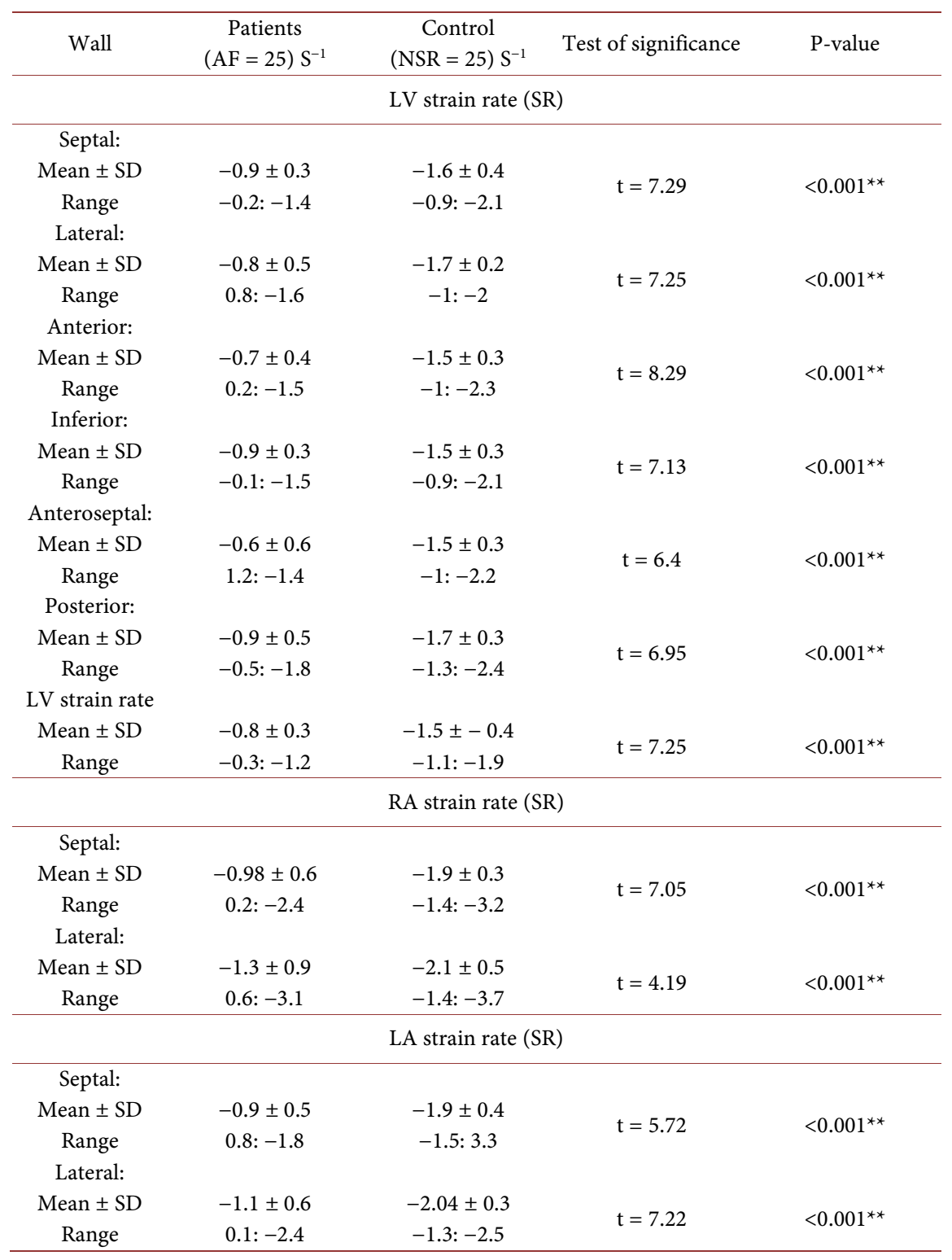




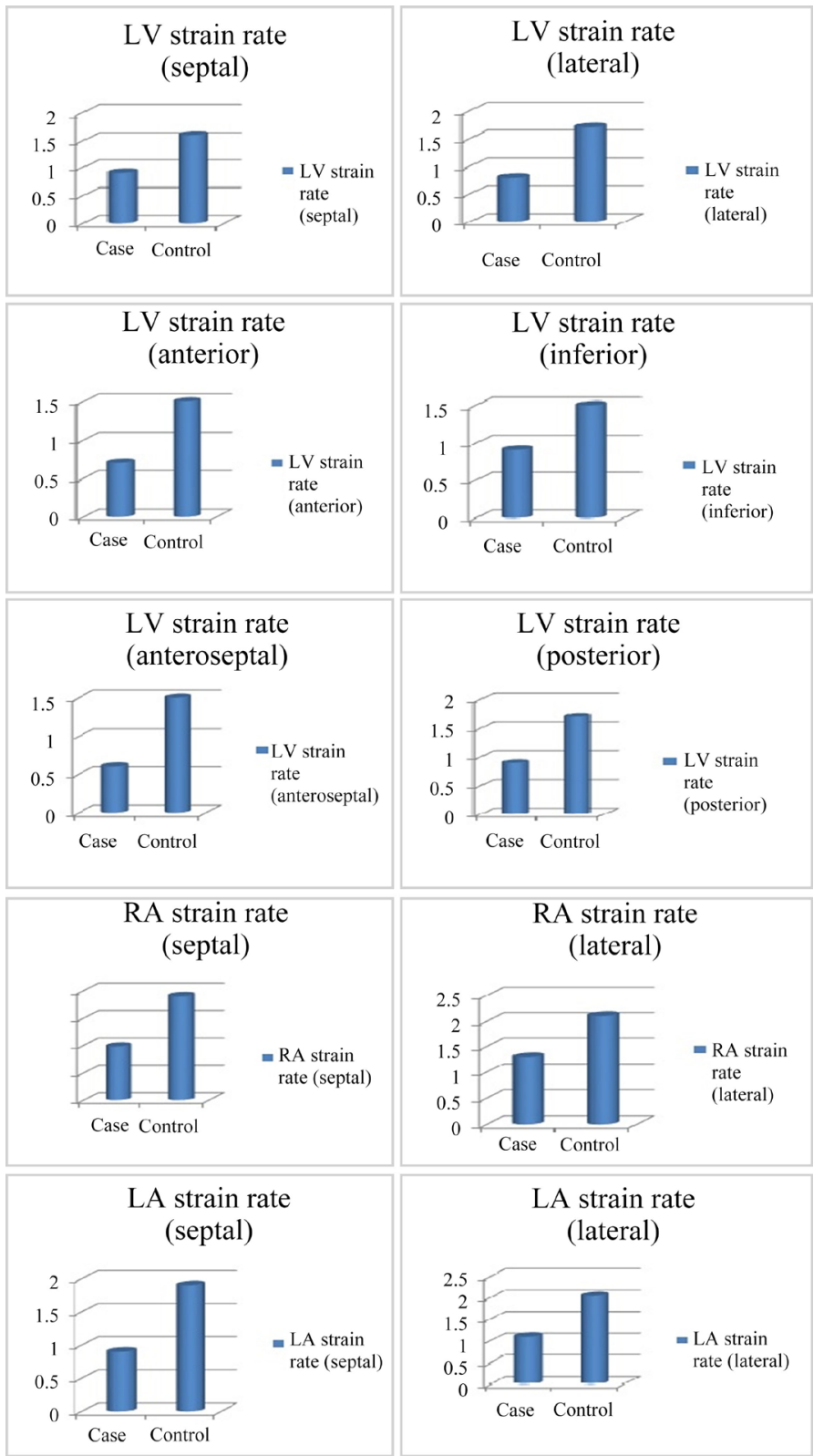

Figure 7. LV, RA and LA SR.

\subsection{Comparison between LA, and RA Strain and Strain Rate in AF Patients}

Table 4 showed the RA strains $(\varepsilon)$ of the septum and the lateral wall, compared to the LA strains $(\varepsilon)$ of the same walls and there was no statistically significant difference between both strains in the AF patients (Figure 8).

\subsection{Comparison between RA and LA Strain Rates (SR) in AF Patients}

Table 5 showed the RA strain rates (SR) of the septum and the lateral wall compared to the LA strain rates (SR) of the same walls and there was no statistically significant difference between both strains in the AF patients except in the strain 
rate for the basal lateral wall, it was significantly higher $(\mathrm{P}$-value $=0.04)$ in the RA than the LA (Figure 9).

Table 4. Comparison between LA, and RA strain in AF patients.

\begin{tabular}{|c|c|c|c|c|}
\hline & \multicolumn{2}{|c|}{ Patients $(\mathrm{AF}=25)$} & \multirow{2}{*}{ Test of significance } & \multirow{2}{*}{ P-value } \\
\hline & RA (\%) & LA (\%) & & \\
\hline Septal: & & & \multirow{4}{*}{$\mathrm{t}=0.79$} & Septal: \\
\hline Mean \pm SD & $-5.9 \pm 6.1$ & $-7.2 \pm 5.2$ & & Mean \pm SD \\
\hline Range & 11.8: -17.7 & 3.6: -17.4 & & Range \\
\hline Lateral: & & & & Lateral: \\
\hline Mean \pm SD & $-8.9 \pm 9.3$ & $-8.7 \pm 8.8$ & \multirow{2}{*}{$\mathrm{t}=0.07$} & Mean \pm SD \\
\hline Range & $16.7:-25.9$ & 3.3: -33.4 & & Range \\
\hline
\end{tabular}

Table 5. Comparison between LA, and RA strain rate in AF patients.

\begin{tabular}{|c|c|c|c|c|}
\hline & \multicolumn{2}{|c|}{ Patients $(\mathrm{AF}=25)$} & \multirow{2}{*}{ Test of significance } & \multirow{2}{*}{ P-value } \\
\hline & $\mathrm{RA}\left(\mathrm{s}^{-1}\right)$ & $\mathrm{LA}\left(\mathrm{s}^{-1}\right)$ & & \\
\hline Septal: & & & \multirow{4}{*}{$t=0.64$} & Septal: \\
\hline Mean \pm SD & $-0.98 \pm 0.6$ & $-0.9 \pm 0.5$ & & Mean \pm SD \\
\hline Range & $0.2:-2.4$ & $0.8:-1.8$ & & Range \\
\hline Lateral: & & & & Lateral: \\
\hline Mean \pm SD & $-1.3 \pm 0.9$ & $-1.1 \pm 0.6$ & \multirow{2}{*}{$\mathrm{t}=0.84$} & Mean $\pm S D$ \\
\hline Range & $0.6:-3.1$ & $0.1:-2.4$ & & Range \\
\hline
\end{tabular}

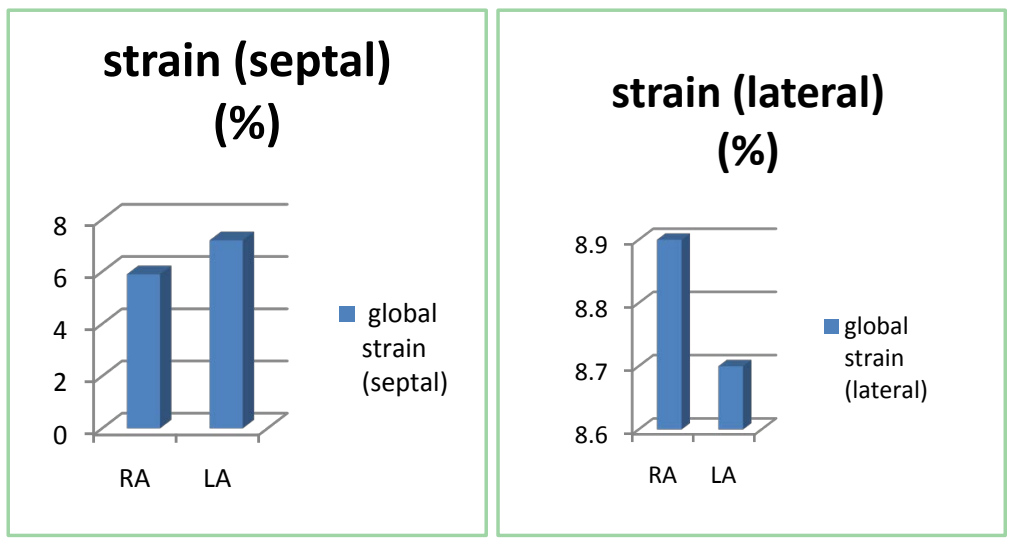

Figure 8. Comparison between LA and RA strain.

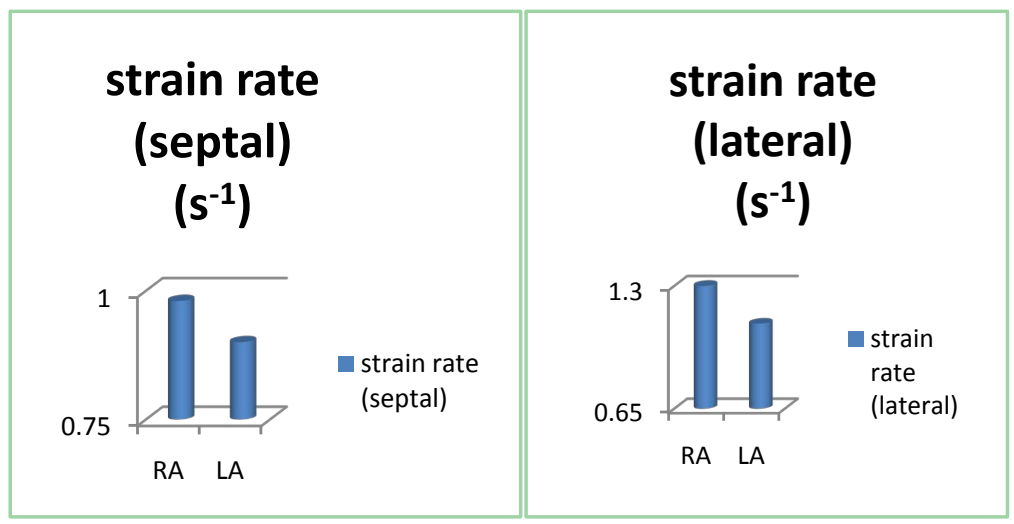

Figure 9. Comparison between LA and RA SR. 


\subsection{Correlation between LA and RA Diameter and LA and RA Total Strains and Strain Rates}

Correlation coefficient (r) interpretation: <0.5: weak correlation, $0.5-<0.6$ : fair, $0.6-<0.7$ : good, $0.7-<0.8$ : strong (very good) correlation * significant correlation, ${ }^{*}$ highly significant correlation.

Table 6 showed that there was a positive correlation between strain of septal wall and lateral wall, strain rate of septal and lateral and RA diameter with statistical significance $(\mathrm{P}$-value $<0.001)$. Also there was a positive correlation between strain rate lateral and RA diameter with statistical significance $(\mathrm{P}$-value $=0.003)$ (Figure 10).

Table 7 showed that there was a positive correlation between strain of septal and lateral wall, strain rate of septal and lateral walls and LA diameter with statistical significance $(\mathrm{P}$-value $<0.001)$ (Figure 11$)$.

Table 6. Correlation between RA diameter and RA total strains and strain rate.

\begin{tabular}{ccc}
\hline & \multicolumn{3}{c}{ RA diameter } \\
\cline { 2 - 3 } RA & $\mathrm{r}$ & P-value \\
\hline Strain Septal & 0.69 & $<0.001^{\star *}$ \\
Strain Lateral & 0.56 & $<0.001^{\star *}$ \\
Strain rate Septal & 0.61 & $<0.001^{* *}$ \\
Strain rate Lateral & 0.42 & $0.003^{*}$
\end{tabular}

correlation between RA diameter and RA total global strains and strain rates

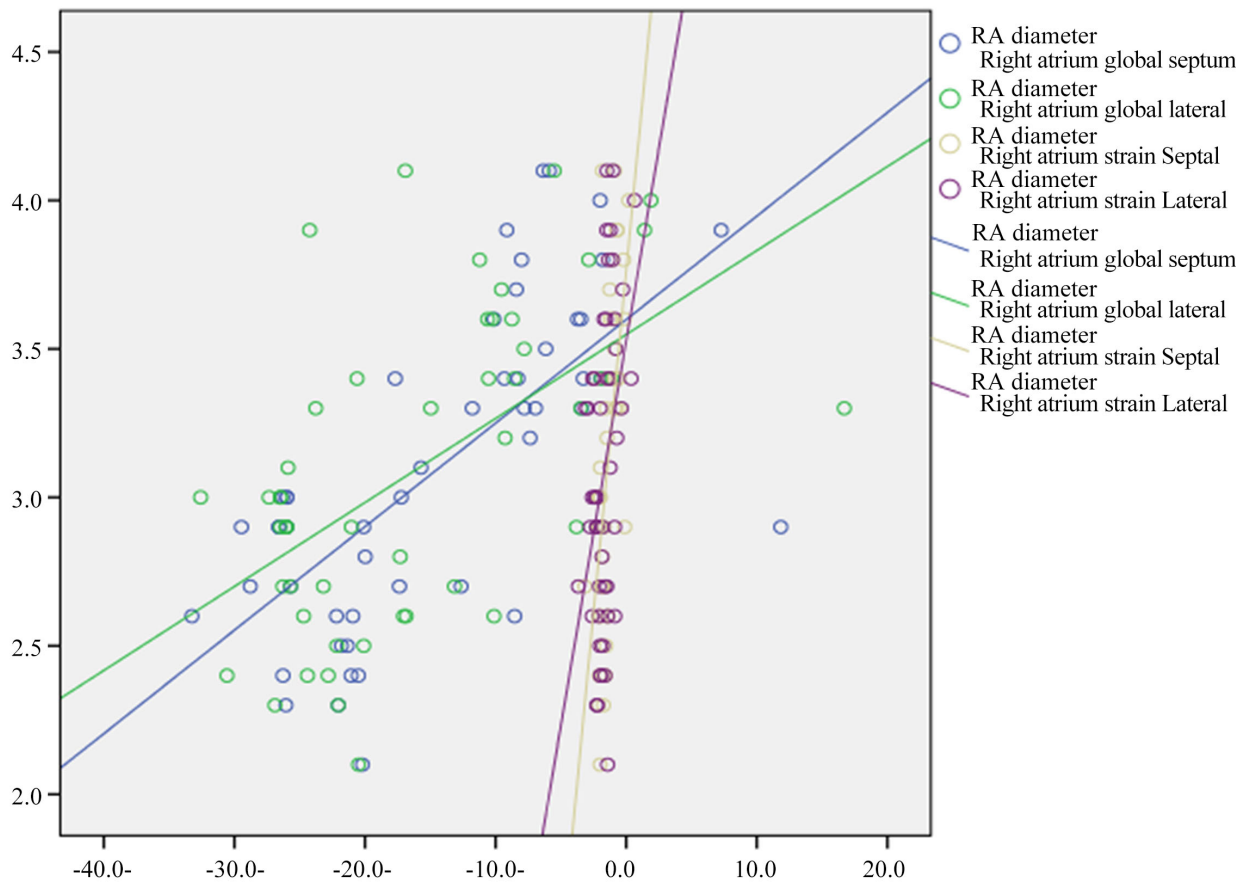

Figure 10. Correlation between RA diameter and RA total strains and strain rate. 
Table 7. Correlation between LA diameter and LA strain and strain rates.

\begin{tabular}{ccc}
\hline LA & \multicolumn{2}{c}{ LA diameter } \\
\cline { 2 - 3 } & $\mathrm{r}$ & P-value \\
\hline Strain Septal & 0.73 & $<0.001^{\star \star}$ \\
Strain Lateral & $\# 0.66$ & $<0.001^{\star \star}$ \\
Strain rate Septal & $\# 0.69$ & $<0.001^{\star \star}$ \\
Strain rate Lateral & 0.66 & $<0.001^{\star \star}$ \\
\hline
\end{tabular}

\#rs: spearman correlation coefficient (not normally distributed data).

correlation between LA diameter and LA total global strains and strain rates

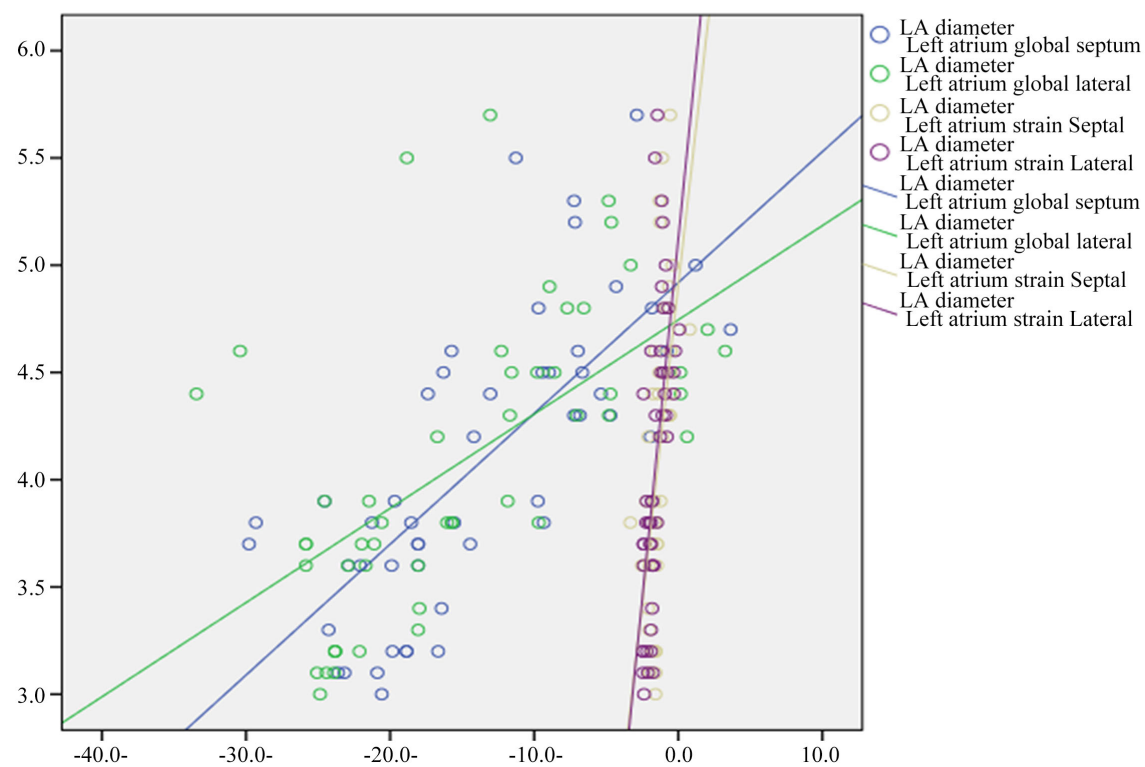

Figure 11. Correlation between LA diameter and LA total strains and strain rates.

\section{Discussion}

Assessment of strain based on 2D speckle tracking allows reliable distinction between active contraction and passive motion [11]. In this study, we describe mainly the relation between non-valvular AF and atrial myocardial deformation (both atria) properties that was significantly impaired in AF patient compared to normal healthy controls. This study demonstrated that there was a relation between atrial dimension and myocardial deformation. We also studied LV global strain in patients with AF. Moreover, we have demonstrated that GLS $(\varepsilon)$ is significantly impaired in AF compared to healthy controls. This study also, demonstrated that there was positive correlation between LA and RA dimensions and LA and RA deformation changes respectively in AF patients. In the present study we found mean longitudinal strain $(\varepsilon)$ of septal wall of left atrium equal $(-7.2 \% \pm 5 \%)$, and mean longitudinal strain $(\varepsilon)$ of lateral wall of left atrium about $(-8.7 \% \pm 8.8 \%)$. Similarly, Hammerstingl et al's study of left atrial deformation imaging with ultrasound based two-dimensional speckle-tracking predicts the rate of recurrence of paroxysmal and persistent atrial fibrillation after 
successful ablation procedures found that the mean longitudinal strain of septal wall of left atrium was $(-14.0 \% \pm 14.1 \%)$ and mean longitudinal strain of lateral wall of left atrium was $(-8.1 \% \pm 7.9 \%)$ [12]. However, study of atrial deformation role in prediction of the maintenance of sinus rhythm after catheter ablation of atrial fibrillation demonstrated that the mean LA strain was $(-16 \% \pm 3 \%)$ in persistent $\mathrm{AF}$ patient and $(-20 \% \pm 3 \%)$ in patient with paroxysmal AF [1]. In our study mean strain rate (SR) of septal wall of left atrium was $\left(-0.9 \pm 0.5 \mathrm{~S}^{-1}\right)$ and mean strain rate (SR) of septal wall of left atrium was $\left(-1.1 \pm 0.6 \mathrm{~S}^{-1}\right)$. Also, a study of Abnormalities of left atrial function after cardioversion by Thomas, Mckay, Byth, et al., demonstrated the mean strain rate of basal septal wall of left atrium was $\left(-0.53 \pm 0.3 \mathrm{~S}^{-1}\right)$ and that of basal lateral was $\left(-1.2 \pm 0.78 \mathrm{~S}^{-1}\right)$ [13] and a comparative study in controls and patients with atrial fibrillation by Inaba et al found that normal values for mean LA strain rate in 50 healthy subjects (29 males and 21 females, age $19-70$ years) was $\left(-3.1 \pm 1.0 \mathrm{~S}^{-1}\right)$ and in $27 \mathrm{AF}$ patient was $\left(-1.7 \pm 0.8 \mathrm{~S}^{-1}\right)$ [14]. This study found that the mean longitudinal strain of septal wall of right atrium was $(-5.9 \% \pm 6.1 \%)$ and mean longitudinal strain of lateral wall of right atrium was $(-8.9 \% \pm 13.6 \%)$ and mean strain rate of septal wall of right atrium was $\left(-0.98 \pm 0.6 \mathrm{~S}^{-1}\right)$ and mean strain rate of septal wall of right atrium was $\left(-1.3 \pm 0.9 \mathrm{~S}^{-1}\right)$. Malini et al. agreed with our study and described that the booster right atrial strain was $(-8 \% \pm 2 \%)$ in a study of role of right atrial strain in prediction of recurrence of attacks of $\mathrm{AF}$ in patient with paroxysmal AF [15]. On the other hand, a speckle tracking echocardiography study demonstrated the role of the right atrium in development of postoperative atrial fibrillation showed that mean right atrial strain $(-15 \% \pm 28 \%)$ [16]. Our study demonstrated that the mean GLS of LV in AF patients was $(-8.8 \% \pm 4.6 \%)$, mean longitudinal strain $(\varepsilon)$ of LV septal wall in AF patient was $(-8.6 \% \pm 5.1 \%)$, mean strain $(\varepsilon)$ of LV lateral wall was $(-9.8 \% \pm 7.04 \%)$, mean strain $(\varepsilon)$ of LV anterior wall was $(-6.8 \% \pm 5.6 \%)$, mean strain $(\varepsilon)$ of LV inferior wall was $(-10 \%$ $\pm 5.8 \%)$, mean strain $(\varepsilon)$ of anteroseptal wall $(-8.2 \% \pm 6.5 \%)$ and mean strain $(\varepsilon)$ of posterior wall $(-9.5 \% \pm 6.9 \%)$. Similarly, Left ventricular systolic function assessed by global longitudinal strain was found in Ross Agner et al. study to be impaired in AF patient compared to NSR either in patient with EF > 50\%) or in those with $\mathrm{EF}<50 \%$ (mean GLS $=-12.85 \% \pm 3.5 \%$ in 75 NSR patient and $-10.10 \% \pm 3.1 \%$ in $75 \mathrm{AF}$ patient) [17]. In contrast, Lee et al.'s study aimed to compare GLS between patients with and without AF in a normal LVEF, to verify whether AF patients have a more impaired GLS and determine whether AF per se is a major determinant of GLS, and evaluate the major determinants of GLS in AF patients, the study found that the mean GLS in 137 NSR patient was $(-15.0 \%$ $\pm 2.8 \%)$ and in $137 \mathrm{AF}$ patient was $(-18.1 \% \pm 3.4 \%)$. In our study we described strain rate $(\mathrm{SR})$ of $\mathrm{LV}$ in $\mathrm{AF}$ patients was $(-0.8 \% \pm 0.3 \%)$ and strain rate of $\mathrm{LV}$ septal wall in AF patient was $\left(-0.9 \pm 0.3 \mathrm{~S}^{-1}\right)$, mean strain rate (SR) of LV lateral wall was $\left(-0.8 \pm 0.5 \mathrm{~S}^{-1}\right)$, mean strain rate (SR) of LV anterior wall was $(-0.7 \pm$ $0.04)$, mean strain rate (SR) of LV inferior wall was $\left(-0.09 \pm 0.3 \mathrm{~S}^{-1}\right)$, mean strain rate (SR) of anteroseptal wall $\left(-0.6 \pm 0.6 \mathrm{~S}^{-1}\right)$ and mean strain rate (SR) of post- 
erior wall $\left(-0.9 \pm 0.5 \mathrm{~S}^{-1}\right)$. While, left ventricular systolic function is assessed by strain rate in Ross Agner et al. study that compared AF patients to NSR and described mean SR in AF patients with reduced EF as $\left(-0.61 \pm 0.2 \mathrm{~S}^{-1}\right)$ and $(-0.90$ $\left.\pm 0.2 \mathrm{~S}^{-1}\right)$ in AF patients with normal systolic function, and $\left(-1.08 \pm 0.3 \mathrm{~S}^{-1}\right)$ in NSR patients with EF > 50\% [17].

\section{Conclusion}

$\mathrm{AF}$ is a bi-atrial disease, LA and RA myocardial deformation properties as well as LV GLS and strain rate values were significantly impaired in atrial fibrillation patients compared to healthy controls.

\section{Recommendation}

From this study, we recommend the following:

1) Future studies have to focus on both atrial myocardial deformation and its impact on understanding behavior of AF pathology and prediction of incidence.

2) Speckle tracking echocardiography is a valuable technique for the assessment of atrial function which may be of clinical relevance for the development of effective strategies to identify patients at high risk of atrial fibrillation.

\section{Conflicts of Interest}

The authors declare no conflicts of interest regarding the publication of this paper.

\section{References}

[1] Schneider, C., Malisius, R., Krause, K., et al. (2008) Strain Rate Imaging for Functional Quantification of the Left Atrium: Atrial Deformation Predicts the Maintenance of Sinus Rhythm after Catheter Ablation of Atrial Fibrillation. European Heart Journal, 29, 1397-1409. https://doi.org/10.1093/eurheartj/ehn168

[2] Benjamin, E.J., Blaha, M.J., Chiuve, S.E., et al. (2017) Heart Disease and Stroke Statistics' 2017 Update: A Report from the American Heart Association. Circulation, 135, e146-e603.

[3] Kirchhof, P., Benussi, S., Kotecha, D., et al. (2016) 2016 ESC Guidelines for the Management of Atrial Fibrillation Developed in Collaboration with EACTS. European Journal of Cardio-Thoracic Surgery, 50, e1-e88.

[4] Nguyen, B.L., Fishbein, M.C., Chen, L.S., et al. (2009) Histopathological Substrate for Chronic Atrial Fibrillation in Humans. Hear Rhythm, 6, 454-460. https://doi.org/10.1016/j.hrthm.2009.01.010

[5] Cianciulli, T.F. (2010) Two-Dimensional Speckle Tracking Echocardiography for the Assessment of Atrial Function. World Journal of Cardiology, 2, 163. https://doi.org/10.4330/wjc.v2.i7.163

[6] Hirose, T., Kawasaki, M., Tanaka, R., et al. (2012) Left Atrial Function Assessed by Speckle Tracking Echocardiography as a Predictor of New-Onset Non-Valvular Atrial Fibrillation: Results from a Prospective Study in 580 Adults. European Heart Journal: Cardiovascular Imaging, 13, 243-250.

[7] Gilman, G., Khandheria, B.K., Hagen, M.E., et al. (2004) Strain Rate and Strain: A 
Step-by-Step Approach to Image and Data Acquisition. Journal of the American Society of Echocardiography, 17, 1011-1020. https://doi.org/10.1016/j.echo.2004.04.039

[8] Kuppahally, S.S., Akoum, N., Burgon, N.S., et al. (2010) Left Atrial Strain and Strain Rate in Patients with Paroxysmal and Persistent Atrial Fibrillation: Relationship to Left Atrial Structural Remodeling Detected by Delayed-Enhancement MRI. Circulation: Cardiovascular Imaging, 3, 231-239. https://doi.org/10.1161/CIRCIMAGING.109.865683

[9] Stiles, M.K., John, B., Wong, C.X., et al. (2009) Paroxysmal Lone Atrial Fibrillation Is Associated with an Abnormal Atrial Substrate. Characterizing the "Second Factor." Journal of the American College of Cardiology, 53, 1182-1191.

https://doi.org/10.1016/j.jacc.2008.11.054

[10] Leitman, M., Lysyansky, P., Sidenko, S., et al. (2004) Two-Dimensional Strain-A Novel Software for Real-Time Quantitative Echocardiographic Assessment of Myocardial Function. Journal of the American Society of Echocardiography, 17, 1021-1029. https://doi.org/10.1016/j.echo.2004.06.019

[11] Hammerstingl, C., Schwekendiek, M., Momcilovic, D., et al. (2012) Left Atrial Deformation Imaging with Ultrasound Based Two-Dimensional Speckle-Tracking Predicts the Rate of Recurrence of Paroxysmal and Persistent Atrial Fibrillation after Successful Ablation Procedures. Journal of Cardiovascular Electrophysiology, 23, 247-255. https://doi.org/10.1111/j.1540-8167.2011.02177.x

[12] Thomas, L., Mckay, T., Byth, K., et al. (2007) Abnormalities of Left Atrial Function after Cardioversion: An Atrial Strain Rate Study. Heart, 93, 89-95. https://doi.org/10.1136/hrt.2006.088609

[13] Inaba, Y., Yuda, S., Kobayashi, N., et al. (2005) Strain Rate Imaging for Noninvasive Functional Quantification of the Left Atrium: Comparative Studies in Controls and Patients with Atrial Fibrillation. Journal of the American Society of Echocardiography, 18, 729-736. https://doi.org/10.1016/j.echo.2004.12.005

[14] Govindan, M., Kiotsekoglou, A., Saha, S.K., et al. (2017) Right Atrial Myocardial Deformation by Two-Dimensional Speckle Tracking Echocardiography Predicts Recurrence in Paroxysmal Atrial Fibrillation. Journal of Echocardiography, 15, 166-175. https://doi.org/10.1007/s12574-017-0341-9

[15] Aksu, U., Kalkan, K., Gulcu, O., et al. (2019) The Role of the Right Atrium in Development of Postoperative Atrial Fibrillation: A Speckle Tracking Echocardiography Study. Journal of Clinical Ultrasound, 47, 470-476.

https://doi.org/10.1002/jcu.22736

[16] Ross Agner, B.F., Katz, M.G., Williams, Z.R., et al. (2017) Left Ventricular Systolic Function Assessed by Global Longitudinal Strain Is Impaired in Atrial Fibrillation Compared to Sinus Rhythm. Journal of Atrial Fibrillation, 10, 1437.

https://doi.org/10.4022/jafib.1437

[17] Lee, H.H., Lee, M.K., Lee, W.H., et al. (2016) Atrial Fibrillation per Se Was a Major Determinant of Global Left Ventricular Longitudinal Systolic Strain. Medicine (Baltimore), 95, e4038. https://doi.org/10.1097/MD.0000000000004038 